\title{
Injury pattern of road traffic accident patients admitted in Assam medical college and hospital, Dibrugarh, Assam
}

\author{
Basanta B. Das, Gourangie Gogoi*
}

Department Community Medicine, Assam Medical College and Hospital, Dibrugarh, Assam, India

Received: 10 December 2015

Accepted: 08 January 2016

\section{*Correspondence:}

Dr. Gourangie Gogoi,

E-mail: drgourangie@gmail.com

Copyright: ( $)$ the author(s), publisher and licensee Medip Academy. This is an open-access article distributed under the terms of the Creative Commons Attribution Non-Commercial License, which permits unrestricted non-commercial use, distribution, and reproduction in any medium, provided the original work is properly cited.

\begin{abstract}
Background: Worldwide 1.24 million people died and 50 million people were injured due to road traffic accidents in 2010. India tops the list of road traffic accident fatality. There is a rising trend in the road traffic accident fatalities in Assam from 2291 deaths in 2012 to 8872 in 2014 . Without appropriate action, by 2030; road traffic injuries are predicted to be the fifth leading contributor to the global burden of disease and injury.

Methods: A hospital based descriptive study was done for duration of one year. All the admitted road traffic accident cases were followed from OPD and Causality registers to the respective departments. After obtaining written consent, data were collected by conducting oral interview using a pre-designed and pre-tested schedule.

Results: Fracture $(71.79 \%)$ was found to be the most common internal injury and Abrasion $(72.8 \%)$ the most common external injury. Injury to brain was found in $16.84 \%$ of the patients. Visceral injuries were found in $10.64 \%$ of the patients.

Conclusions: Motor vehicle injuries are major cause of both external and internal injuries. There is importance of identifying typical patterns of injury associated with road traffic accidents. It may help in the logical management of the victims and capacity building of trauma centres according to regional needs.
\end{abstract}

Keywords: Road traffic accident, Injury, Injury pattern

\section{INTRODUCTION}

Road traffic injuries are estimated to be the eighth leading cause of death globally, with an impact similar to that caused by many communicable diseases, such as malaria. ${ }^{1}$ Worldwide in addition to the 1.24 million deaths around 50 million people are injured in road traffic accidents. The actual toll may be even more as the non-fatal crashes are poorly reported and documented. ${ }^{1}$ In India the magnitude of the problem is alarming. More people die in road traffic accidents in India than anywhere else in the world, including the more populous China. ${ }^{1}$ In 2010, a total of 65225 people died in China whereas, in India 133938 people died due to road traffic accidents. Assam in the north east of India has a high rate of accidents. A total of 2342 persons lost their lives during 2011. 2291 persons lost their lives in 2012. The death toll increased to 2441 in 2013. 2 Dibrugarh, a notable district of Assam, has a high rate of road traffic accident. As per the data of Medical Records Department of Assam Medical College and Hospital a total of 757 road traffic accident cases were admitted in Assam Medical College and Hospital in 2011, 577 cases in 2012 and 711 cases in 2013.

\section{METHODS}

Hospital based descriptive study was carried out over a period of one year from April 2014 to March 2015 at Assam Medical College and Hospital, Dibrugarh.

Study population: Road traffic accident case data were collected from the Medico legal register, Department of 
Casualty and Outpatient department of Assam Medical College and Hospital and the admitted cases were followed to the respective departments for interview. Written permission was taken from the Principal, Assam Medical College and Hospital, Dibrugarh to allow for interviewing the road traffic accident patients in the respective departments.

Sample size: All the road traffic accident patients who were admitted in the various departments of Assam Medical College and Hospital were included in the study.

Data collection tools and technique: After accessing the initial information about the road traffic accident patient from the medico legal register of Department of casualty and Out Patient Department the study participants were followed to the respected department. The study participants were carefully briefed regarding the purpose of the study and their consent taken so as to obtain their full co-operation for the study. Data were collected by interviewing the road traffic accident patient from the clinical and diagnostic reports and examination of the patient where ever necessary.

Inclusion criteria: All the road traffic accident patients admitted in various departments of Assam Medical College and Hospital who gave consent to participate in the study.

Exclusion criteria: The following cases were excluded from the study -

- Cases discharged from OPD and Casualty.

- Brought dead cases.

- Cases admitted in the intensive care unit.

- Cases not willing to participate in the study.

- Cases dying after admission before interview.

The anatomical site of injury: For region wise distribution of injuries, the human body was divided into the following five regions ${ }^{3}$ :

- Head and Neck

- Thorax

- Upper limb

- Abdomen and Perineum

- Lower limbs

Type of injury- Injuries were classified into the following types: ${ }^{4,5}$

\section{External injury}

Abrasion: Destruction of the skin involving the superficial layers of epidermis.

Bruise: Effusion of blood into the tissues due to the rupture of blood vessels.
Laceration: Tears or splits of skin, mucous membrane, muscle or internal organs.

\section{Internal injury}

Fracture: Damage in the continuity of a bone.

Dislocation: Abnormal separation in the joint where two or more bones meet.

Trauma to brain: Trauma to the brain along with its membranes.

Visceral injuries: Trauma to the internal organs of thorax, abdomen including pelvic cavity and retroperitoneal organs.

\section{RESULTS}

A total of 677 road traffic accident patients were interviewed. Out of these $87.3 \%$ were male. Majority (33.8\%) belonged to $16-25$ years age group. A major proportion $(41.1 \%)$ of the RTA patients was educated up to middle school. Majority of the RTA patients belonged to BG Prasad's socioeconomic class IV. A major proportion $(34.4 \%)$ of the RTA patients was daily wage earners by occupation. Majority (37.4\%) of the RTA patients were pedestrians. The results and observations are summarised as below.

Table 1: Different types of injuries recorded in the RTA patients.

\begin{tabular}{|lll|}
\hline Type of injury & Frequency & Percentage \\
\hline Fracture & 794 & 38.04 \\
\hline Dislocation & 34 & 1.63 \\
\hline Head injury & 114 & 5.46 \\
\hline Visceral injury & 72 & 3.45 \\
\hline Abrasion & 811 & 38.86 \\
\hline Bruise & 145 & 6.95 \\
\hline Laceration & 117 & 5.61 \\
\hline Total & 2087 & 100 \\
\hline
\end{tabular}

Table 2: Distribution of the RTA patients sustaining visceral injury according to injury type.

\begin{tabular}{|lll|}
\hline Type of injury & Frequency & Percentage \\
\hline $\begin{array}{l}\text { Unspecified } \\
\text { Haemoperitoneum }\end{array}$ & 44 & 61.11 \\
\hline Pneumothorax & 9 & 12.5 \\
\hline Splenic rupture & 7 & 9.72 \\
\hline Liver laceration & 12 & 16.66 \\
\hline Total & 72 & 100 \\
\hline
\end{tabular}

Fracture was recorded in $71.79 \%$ of the road traffic accident patients. Fracture femur was the most common $(20.4 \%)$ fracture recorded. 
Dislocations were recorded in $5.02 \%$ of the RTA patients. Shoulder joint was the most common $(61.76 \%)$ joint to dislocate. Injury to brain was recorded in $16.84 \%$ of the RTA patients. Visceral injuries were recorded in $10.64 \%$ of the RTA patients.

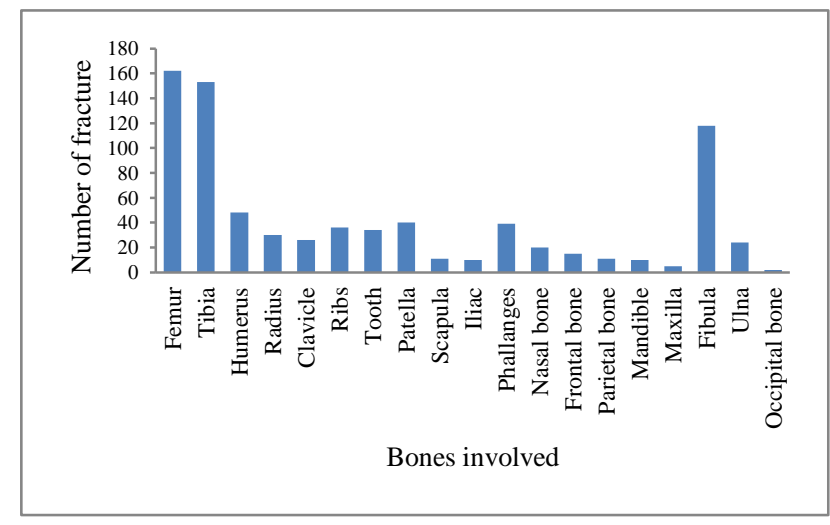

Figure 1: Distribution of types of fracture among the RTA patients.

Majority of the visceral injury were sustained by pedestrians $(43.28 \%)$ whereas, major portion of the fractures were recorded in drivers $(35.19 \%)$.

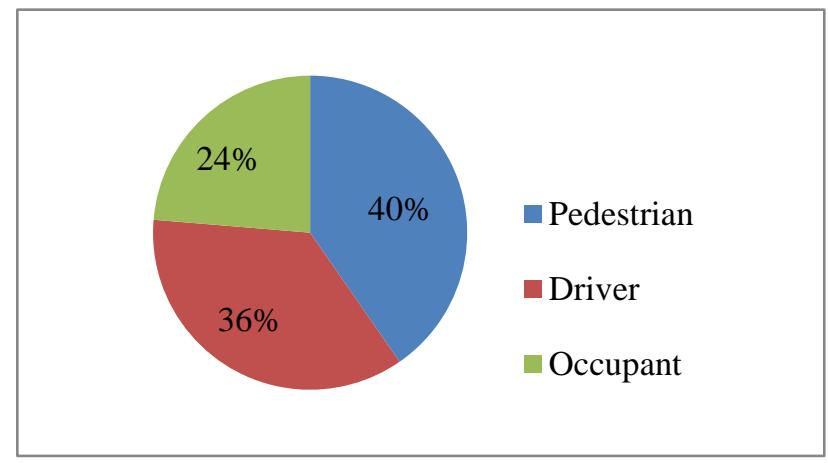

Figure 2: Distribution of the brain injury in different types of road user.

Abrasion was recorded in $72.8 \%$ of the RTA patients. Majority of the abrasions were sustained in upper limb $(52.74 \%)$. Bruise was found to be present in $16.69 \%$ of the RTA patients. A major proportion (48.28\%) of the bruises was located over head and neck region. Laceration was present in $16.4 \%$ of the road traffic accident patients. Majority $(63.25 \%)$ of the lacerations was present over head and neck region.

\section{DISCUSSION}

In the present study fracture was recorded to be the most common type of injury. Similar findings were recorded by GB Ganveer and RR Tiwari in a study "Injury pattern among non-fatal injury cases: A cross sectional study in central India". 6
Majority of the fractures $(62.47 \%)$ were located in lower limb. Similar findings were reported by R Singh, HK Singh, SC Gupta and Y Kumar in a study "Pattern, Severity and Circumstances of Injuries Sustained in Road Traffic Accidents: A tertiary care hospital-based study". ${ }^{7}$

In the present study extradural haemorrhage was found to be the most common (27.19\%) form of brain injury. Contrary to the present study R Ravikumar in a study "Patterns of head injuries in road traffic accidents involving two wheelers: An autopsy study" reported extradural haemorrhage to be the least common form of head injury. ${ }^{8}$

\section{CONCLUSION}

Majority of the reported patients in our study were females, majority were in the economically productive age group, majority were educated up to high school and above and majority of patients belonged to lower socio economic class. Most common illness among patients in our study was pain abdomen followed by knee pain and cough/cold. The most commonly affected organ systems were musculoskeletal, gastrointestinal and skin, reproductive as well as respiratory system. Cough/cold followed by fever were the most common presenting complaints among preschool as well as school children. Knee pain followed by generalized body aches and pain abdomen were the most common illnesses among the elderly patients.

\section{ACKNOWLEDGEMENT}

I extent my heartiest thanks to Dr. H. Saikia, MPhil, PhD (Statistics), Senior lecturer, Department of Community Medicine, Assam Medical College and Hospital for his help, counsel and guidance in statistical analysis of this study.

\section{Funding: No funding sources}

Conflict of interest: None declared

Ethical approval: The study was approved by the Institutional Ethics Committee

\section{REFERENCES}

1. Global status report on road safety 2013. Luxemberg: WHO, Switzerland. 2013:1-7.

2. Department of Transport, Government of Assam, Website www.assamtransport.gov.in/statistics.htm accessed on 2nd October 2015.

3. Chaurasia BD, Human anatomy, Chennai, CBS publishers and distributors Ltd., $6^{\text {th }}$ ed.

4. Knight B, Saukko P. Knight's forensic pathology, London, $3^{\text {rd }}$ edition, Edward Arnold Ltd., 281-296.

5. Reddy KSN. The essentials of forensic medicine and toxicology, Hyderabad. Om Sai graphics. 2012;31:224-67. 
6. Ganveer GB, Tiwari RR. Injury pattern among nonfatal injury cases: A cross sectional study in central India. Indian J Med Sci. 2005;59(1):9-12.

7. Singh R, Singh HK, Gupta SC, Kumar Y. Pattern, Severity and Circumstances of Injuries Sustained in Road Traffic Accidents: A Tertiary Care HospitalBased Study, Indian J community Med. 2014;39(1):30-4.
8. Ravikumar R. Patterns of head injuries in road traffic accidents involving two wheelers: An autopsy study. J Indian Acad Forensic Med. 2013;35(4):349-52.

Cite this article as: Das BB, Gogoi G. Injury pattern of road traffic accident patients admitted in Assam medical college and hospital, Dibrugarh, Assam. Int J Community Med Public Health 2016;3:482-5. 